\title{
Ethnic Socialization: A Case of Malaysian Malay and Chinese Public Universities Students Experiences
}

\author{
Chin Yee Mun
}

\begin{abstract}
By and large, Malaysians associate themselves with certain ethnic identities. Such identification is clearly visible in most Malaysian public universities. This paper relates Malaysian Malay and Chinese public universities students' ethnic identification to their ethnic socialization experiences. Focus group discussions with Malay and Chinese students were conducted in four Malaysian public universities. Outcomes from the focus group discussions reveal the roles of cultural and competition socialization experiences in constructing the students ethnic identity. These ethnic socialization experiences played an important role in constructing ethnic consciousness among the students.
\end{abstract}

Index Terms-Ethnic, ethnic identity, ethnic socialization

\section{INTRODUCTION}

Social constructionists such as M. Banton [1] and J. Nagata [2]) elaborate ethnic as a form of social category. It exists due to ethnic group members' presumptions that they are associated through sharing of certain common traits. As discussed by C. Geertz [3], the common traits developed a sense of 'blood ties' among members of a particular ethnic group. Language, religion, place of origin, descent and cultural practices are used by group members to construct the ties. Often, the bindings caused them to feel that they are morally responsible for the well being of their ethnic group. Hence, ethnic group is a constructed identity, formed by its members to socially categorize themselves and others as members of distinctive groups.

In the context of a multi-ethnic society such as Malaysia, such identification prevails. According to T.G. Lim [4], Malaysians identify themselves as Malay, Chinese, Indian, Iban, Kadazan, Orang Asli and numerous other ethnic and sub-ethnic groups. This paper intends to explain Malaysian ethnic socialization processes and the consequence of such socialization. As a result of these processes, Malaysians identify themselves as members of different ethnic groupings. In other words, this paper will explain Malaysian ethnic socialization. Through ethnic socialization, Malaysians garnered experiences that guided them to identify themselves as members of a particular ethnic group. Further discussion in this paper will reveal the fact that these experiences are outcomes of the interplay between ethnic groups' members collective commitment to enhance their solidarity and members willingness to acknowledge

Manuscript received May 29, 2013; revised July 23, 2013. This work was supported in part by the Universiti Tunku Abdul Rahman Research Fund under grant $6200 / \mathrm{C} 36$

Chin Yee Mun is with the Department of General Studies, Faculty of Creative Industries, Universiti Tunku Abdul Rahman, Petaling Jaya, Selangor, Malaysia (e-mail: chinym@utar.edu.my) themselves as members of their ethnic groups.

Ethnic groups have been mobilized to become a collective movement to champion members' rights. Factors and conditions that caused Malaysians to utilize such mobilization will be discussed in the second section of this paper. In the third section, information concerning research methodology will be presented. Discussion on the findings will be presented in the fourth and fifth section.

\section{SOCIAL CONDITIONS AND ETHNIC SOCIALIZATION IN MALAYSIA}

Large-scale migration of Chinese and Indian labourers to the Malay Archipelago in the nineteenth century had contributed to the formation of Malaysian multi-ethnic society. Due to huge demands for labourers to work in tin mines and plantations, many Chinese and Indians were brought in. However, not all Chinese and Indians were brought in for such purposes. According to K. K. Khoo [5], some came through personal initiative. Gradually, their numbers increased. Subsequently, the Chinese and Indian immigrants formed their communities. This development had caused K. J. Ratnam [6] to conclude that by the time Malaya achieved independence in 1957, the number of nonMalays (Chinese and Indian) equalled the Malays. There were little interactions between them and the locals - the Malays. The non-Malays continued to practise their languages, beliefs, values and norms and these practices made them distinctive. Their reluctance to mingle and to be assimilated had finally caused the emergence of plural society in the Malay Peninsula. When Malaya, Sabah and Sarawak agreed to merge to form Malaysia in 1963, the plurality of Malaysian society became more diverse. Besides Malay, Chinese and Indian, native groups of Sabah and Sarawak became part of the Malaysian society.

What could have caused Malaysians to retain their ethnic identity? Why would they prefer to identify themselves as members of certain ethnic groupings? Some scholars such as M. Banton [1] opined that ethnic identity is constructed voluntarily by individuals. Through such identification, an individual will be able to associate himself with certain ethnic groupings. Being a member of an ethnic group, he will be able to participate in a collective movement to compete with individuals from other groups more effectively. It is their choice after considering situations that may or may not favour their wellbeing and goals. If they find their goals are obtainable through personal effort, their tendency to associate themselves to their ethnic groups may not be strong. Contrarily, if they find their goals cannot be achieved though individual effort, the tendency to associate themselves to their ethnic group will be strong. S. Fenton [7: 
6] suggested a more or less similar approach in understanding the formation of ethnic groups. According to him, people act in accordance to conditions. In certain conditions, people will take their cultural and descent identities seriously but in some other conditions, ethnic identity will be treated as trivial and unimportant. Thus, the formation of ethnic groups will largely depend on an individual choice. In most of the time, it is used to forge collective action to compete with members from other ethnic groups. Ethnic identity is therefore an expression of a self-navigated direction that shapes and reshapes an individual perception on others as well as those of their own. As such, when Malaysians identify themselves as members of different ethnic groups, there is a possibility that they voluntarily do so to form a collective movement to secure their needs. Various conflicts that have occurred such as the May $13^{\text {th }} 1969$ racial riot have proven this point. According to W. T. Wan Hashim [8], economic disparity between Chinese and Malay had caused the riot. The riot proves the fact that Malaysians are ethnically conscious and the consciousness is a mean to form collective action to compete with others. Eventually, the competition to secure access to economic resources contributed to ethnic conflict. However, such consciousness will not emerge unless there is a collective effort to spur it. Members of a particular ethnic group will have to be socialized to develop his or her ethnic consciousness.

Ethnic socialization is then a collective effort imposed by members of an ethnic group to build ethnic consciousness. According to J. J. Arnett [9], family and peers from the same ethnic group provide the most effective ethnic socialization experiences. The high frequency of interactions with family members has made family an effective agent in promoting ethnic solidarity. Interactions with peers are also effective in inculcating ethnic consciousness. The freedom of expression among peers will provide them an effective room in influencing each other view. Through these agents of socialization, members of an ethnic group will learn about the history and culture of their ethnic group. D. Hughes et al., [10] classified these experiences as cultural socialization. The members will also learn that other groups have biased perceptions which are against them. As a result they learn not to trust members of other ethnic groups. These experiences provided the members a sense of belonging that was described by Nagata [2: 189] as a form of "ideological bund". According to Nagata, the process will caused members of an ethnic group to feel that they have a moral obligation to be loyal to their ethnic group.

Further discussion in this paper will explore the types of ethnic socialization Malaysians went through. In order to explore this phenomenon, the author chose to conduct his research in Malaysian public universities. The decision to conduct this research in the universities was made after considering the occurrence of ethnic polarization in these institutions. Reports from studies conducted by D. Fatimah [11] and T. Helen [12] show intense ethnic polarization among Malaysian students. Respondents of Fatimah's research were reluctant to share hostel rooms with students from other ethnic groups. Meanwhile, Helen's observation revealed the fact that ethnic polarization has occurred in
Malaysian public universities since the establishment of University of Malaya, Malaysia oldest public university.

\section{RESEARCH METHODOLOGY}

Eight focus group discussions (FGD) were held in four Malaysian public universities to explore the students' ethnic socialization experiences. The decision to use FGD as the data collection method was made after considering the advantages of this method. Through this method, this research would be able to obtain in-sights from the students who were the 'actors'. Qualitative data obtained through this method would be able to complement quantitative data obtained from previous research. The universities are Universiti Sains Malaysia (USM), Universiti Putra Malaysia (UPM), Universiti Kebangsaan Malaysia (UKM) and University of Malaya (UM). Four FGDs were held with the Malay students and another four were held with the Chinese students. In each group the proportion of male and female students were equal.

This method was employed after considering the fact that the research propositions require this research to be conducted in a qualitative manner. The propositions require this research to capture the views of the actors on their experiences and interpretations. Instead of using a quantitative approach which confines this research to certain presumed relationships between the factors influencing the students socialization experiences, this research engaged the qualitative approach. Through the qualitative approach, this research would be able to capture the students' ethnic socialization experiences that had contributed to the construction of their ethnic consciousness.

Approximately 60 Chinese and Malay students were involved in the FGDs. In each FGD group, there were six to eight discussants and the time spent on each FGD ranges from one hour forty five minutes to two hours and fifteen minutes. The usage of FGD as the data collection method allowed this research to achieve theoretical saturation since views from many discussants were taken into consideration to formulate a category of data. Saturation of data was achieved when similar ideas and opinions were shared by the students. Data from each FGD was analysed by using grounded theory analysis method. In order to form a category of data, the data obtained from one FGD went through three level of coding. The three levels were open coding, axial coding and matrix/conditional coding. The data was then compared against data from other FGDs held in other universities to form a firmer saturation.

\section{FINDINGS AND DISCUSSIONS}

Ethnic identity and boundary are constructed individually. As highlighted earlier, individuals' needs are the primary factor that caused the formation of ethnic groups. Their needs create the necessity to form ethnic groups. Banton's [13] observation on the factors that contributed to ethnic conflicts pinpointed competition for power and economic advantages as the main reasons that caused the conflicts to happen. In the case of Malaysia, such contestations have metamorphosed into ethnic groups' competition. As 
suggested by Shamsul A. B. [14], the Chinese in Malaysia felt the Malays have marginalized them and the Malays felt the Chinese are competing against them to gain control over this country. The contentions have aroused their ethnic consciousness. Collective actions were taken by members of both groups to strengthen ethnic solidarity.

Hence, ethnic consciousness is constructed by individuals who feel that they need group support to fulfil their goals. Consequently, ethnic consciousness in Malaysia became strong. Under such circumstance, ethnic groups in Malaysia prevail. In Malaysian public universities, the consciousness is evident. Besides Fatimah [11] and Helen [12], other researchers such as M. N. Noraini [15] and E. Yeoh [16] had also revealed the occurrence of ethnic polarization in Malaysian public universities through their researches.

As will be highlighted later, the Malay and Chinese students ethnic identity are not 'given'. According to C. Geertz [3], members of an ethnic group assume that their relationship is 'given'. This assumption caused the members to form primordial ties. Nevertheless, Nagata [2] disagreed with C. Geertz. For Nagata, the assumption is developed when members of an ethnic group try to develop association among them. This has caused them to primordialize their ethnic traits. In other words, ethnic consciousness is an outcome of actions taken by the members of an ethnic group to commit their alignment to their ethnic group. They demarcate their differences by referring to their sociocultural and biological features. The demarcations are not imposed. It is a method used by individuals to differentiate themselves from members of other ethnic groups. Through their collective commitment, ethnic groups are transformed into political movements. These movements are able to organize and manoeuvre itself to compete with members of other ethnic groups. In order to generate such effects, ethnic socialization is initialized by members of the groups such as family members and peers. Following discussion will reveal that the experiences form the pillars for a structuralized process that caused Malay and Chinese students in Malaysian public universities to develop their ethnic consciousness and subsequently identify themselves according to ethnic lines.

\section{A. Cultural Socialization}

Through cultural socialization, members learn about the beliefs, values, norms and traditions of their ethnic groups. In the case of the Malay students', they felt, their family had exposed them to the Islamic practices and Malay cultures. According to AJ (a USM Malay student):

... My parents taught me the Malay's taboos although the taboos may not be relevant anymore... According to them, girls are not allowed to sing while in the kitchen ... Girls are also not allowed to hang around outside their house...

Her description of her family socialization experience clearly reflects her family role in instilling the knowledge pertaining to Malay traditional beliefs. While AJ's family shared with her knowledge that are related to Malay traditional practices, ST (UPM student) parents emphazised Islam as the Malay religion. According to ST, her parents told her that Malay culture and traditions must be based on Islamic principles. Therefore, by practising Islamic principles, she would also practise Malay cultural practices and traditions. The Chinese students shared similar experiences. They too felt their family socialization experiences had provided them knowledge concerning Chinese cultural practices and traditions. SK (UM student) described her experience:

When I was small, I was asked to wear red cloths during Chinese New Year. My mother will pray to my ancestors by burning worship papers. All these childhood memories, are part of my Chineseness.

D. Hughes et al., [10] suggested that the transmission of these knowledge is important to promote cultural and traditional practices awareness. Through the awareness, the students are aware of the nature of their ethnic groups' cultural and traditional practices. It provided them explanations concerning their ethnic identity. However, these explanations will transformed into ethnic boundaries that are used by the students to distance themselves from members of other ethnic groups.

The role of family socialization in constructing ethnic identity includes the inculcation of ethnic pride. The purpose of such inculcation is to promote a sense of loyalty among ethnic group members as well as enhancing the sense of belonging. LL, a Chinese student who is pursuing a linguistic degree at UPM believes that the Chinese have superior business skill if compared to other ethnic groups in Malaysia. When asked about the source of such belief, she replied, "My family will say Chinese is good in business. They will compare Chinese with Malays... Malays set up small shop. Chinese will not do that... I am proud of Chinese." Judging from her reply, it is apparent that her family tried to instil ethnic pride in her by comparing Chinese and Malay. Similar experience was shared by FT, a Malay student who is pursuing material science degree in UPM. Her family often reminded her that the Malays have higher social etiquette if compared to other ethnic groups.

\section{B. Competition Socialization}

While family play an important role in instilling knowledge pertaining to their cultural and traditional practices, interactions with peers provide the students information concerning the position of their ethnic group in the Malaysian society. Interactions with peers are often open and therefore sharing of information is often direct and informative.

UKM's Malay FGD participant, AR shared her experience with her Malay peers. According to her, “...I started to differentiate Malay and others when I was in my secondary school. My friends asked me to be not so close with the non-Malays. Non-Malays are non-Muslims..." Her experience shaped her perception. It instilled in her the thought of not trusting people from other ethnic groups. Her university mate, NM shared another experience with similar effect. Her friends told her that the Chinese students were calculative and stingy. NM admitted that such information had affected her views. Similar experiences were shared by the Chinese students. YX was one of such Chinese students. He said:

... they (the Malays) really enjoy their time even if there is a deadline. Let say there is a conference.... they spend three hours enjoying food and two hours on conference. They are very laid-back. Me and others... we share such information. 
Ah... you have the same experience... so that makes our feeling stronger.

YX experience indicated that he shared views concerning the Malays students with his Chinese friends. The sharing caused them to perceive the Malay students as laid-back and therefore would not be suitable people to collaborate with. Other interesting comments made by the Chinese students were about the Chinese reaction to their position in Malaysia. According to ST who was pursuing social science degree at USM, the marginalization had caused the Chinese students in her university to work hand in hand. This means, among the Chinese students, there is a collective effort to withstand the perceived marginalization. Such effort to promote ethnic solidarity was also observed in the Malay students FGDs. According to AM (a UKM student), he and his friends would support and campaign for a Malay candidate in their campus election. Although not stated clearly by AM, his opinion indicated that he would like to preserve their ethnic group solidarity.

The above discussion concerning Malay and Chinese students' ethnic socialization experiences clearly reflect the presence of their ethnic group collective effort to instil ethnic group solidarity. There seems to be a collective effort from their ethnic group peers to promote mistrust. Such effort was reflected in the students' ethnic socialization experiences. They were told that their ethnic group position had been compromised. They were also told that other ethnic groups practise beliefs, values and norms that were not 'up to the standard' of their ethnic group. Their peers' discussed issues concerning the position of their ethnic group in Malaysian society. As a result, such collective effort would produce initiative by the students to strengthen ethnic solidarity to compete with members of ethnic groups. Similarly, family members played crucial roles in shaping the students ethnic consciousness. Judging from the above discussion, there were efforts made by the students' family members to instil ethnic pride and the sense of belonging to the students.

\section{CONCLUSION}

The discussion above provides evidences that ethnic polarization in Malaysian public universities maybe an unavoidable social phenomenon. It is evident that their socialization experiences will caused them to construct ethnic consciousness. The consciousness caused them to identify themselves as Chinese or Malay and view others as "others".

As observed by M. Banton [1] and Nagata [2], there is interplay between individual efforts to form ethnic solidarity and the collective efforts of other members. While an individual is trying to exploit the collective action of his ethnic groups, he has inadvertently spurred an ethnic based collective action to construct ethnic solidarity. The narrations provided by the students are evidences that can prove the validity of such observation. Through their socialization experiences, they learned about their ethnic identity. The learning taught them to perceive themselves as a Malay and Chinese. Further exposures to the ethnic socialization experiences have caused them to perceive the position of their ethnic groups have been threatened and as a result the experiences generated the urge to form ethnic solidarity. The approach suggested by social construction scholars proves ethnic consciousness at the individual level plays a vital role in ensuring the perseverance of ethnic group. In the Malaysian context, Malaysians will continue to identify themselves according to ethnic lines. This is because ethnic group can be and has been mobilized to form collective movements that may benefit them.

\section{REFERENCE}

[1] M. Banton, "A Theory of Social Category," Sociology, vol. 45, pp 187-201, 2011.

[2] J. Nagata, Malaysian Mosaic: Perspectives from a Poly-ethnic Society, Vancouver: University of British Columbia Press, 1979.

[3] C. Geertz, The Interpretations of Culture, London. Hutchinson \& Co, 1973.

[4] T. G. L. Gomes and A. A. Rahman, Multiethnic Malaysia: Past, Present and Future, Petaling Jaya: SIRD, 2009.

[5] K. K. Khoo, "The Emergence of Plural Communities in the Malay Peninsular before 1874," in Multiethnic Malaysia: Past, Present and Future. T. G. Lim, Gomes, A. \& Azly Rahman. Petaling Jaya: SIRD, 2009, pp. 11-32.

[6] K. J. Ratnam, Communalism and the Political Process in Malaya, Kuala Lumpur: University of Malaya Press, 1967.

[7] S. Fenton, Ethnicity, Cambridge: Polity Press, 2011

[8] W. H. W. Teh, Race Relations in Malaysia, Kuala Lumpur: Heinemann Educational Books, 1993.

[9] J. J. Arnett, "Broad and Narrow Socialization: The Family in the Context of a Cultural Theory," Journal of Marriage and Family, vol. 57, pp. 617-628, 1995.

[10] H. D. Rodriguez, J. Smith, E. P., D. J. Johnson, C. H. Stevenson, and P. Spicer, "Parents Ethnics, Racial Socialization Practices: A Review of Research for Future Studies," Developmental Psychology, vol. 42 pp. 747-770, 2006.

[11] D. Fatimah, "Polarisasi Kaum dalam Kalangan Pelajar Universiti," in Mohd. Fauzi Yaacob. (ed.)., Malaysia: Menangani Perubahan dan Pembangunan, Kuala Lumpur: University of Malaya, 2006.

[12] T. Helen, "Interethnic Relation in Malaysian Campuses: A Historical Review,"Malaysian Journal of Chinese Studies. vol. 1, pp. 60-84, 2012.

[13] M. Banton, "Ethnic Conflict," Sociology, vol. 34, pp. 481-498, 2000.

[14] A. B. Shamsul, "Debating about Identities in Malaysia: A Discourse Analysis," Southeast Asian Studies, vol. 34, no. 3, pp. 476-499, 1996.

[15] N. M. Noor, "Polarization and Inequality in Malaysia: The Future of Malay-Chinese Relations," Intellectual Discourse, vol. 15 pp 191-204, 2007.

[16] E. Yeoh, "Ethnic coexistence in a pluralistic campus environment," GeoJournal, vol. 66, pp. 223-241, 2006

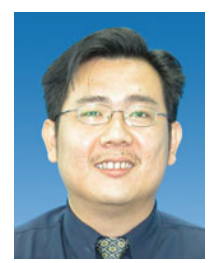

Chin Yee Mun graduated with a bachelor degree in anthropology and sociology from University of Malaya in 1998. He continued his studies in University of Malaya and was awarded Master of Art degree in 2001. Currently, he is a senior lecturer in Universiti Tunku Abdul Rahman (UTAR) and has been assigned to teach subjects related to Sociology and Malaysian Studies. Before joining UTAR in 2004, he had worked as lecturer in Inti College Malaysia and Sunway College Malaysia. Due to his interest in research related to ethnic relations and culture, he was involved in several research projects in these areas. One of the projects studies the worship of Datuk Gong in Malaysia. Other researches include studies pertaining to Chinese women zuo yuezi practice and ethnic relation in Malaysia. Output from his researches were presented in conferences and published in journals and magazines. 